\title{
Magnesium Influence on Stress and Immune Function in Exercise
}

\section{L.R. Brilla*}

PEHR Department, Western Washington University, Bellingham, USA

Magnesium (Mg) may enhance physical activity through a number of associated mechanisms: all phosphotransfers, a cofactor to over 325 enzymatic reactions, protein synthesis, and electrolyte balance $[1,2]$. About $60 \%$ of adults in the United States do not consume the estimated average requirement of $\mathrm{Mg}$, yet widespread pathological conditions attributed to $\mathrm{Mg}$ deficiency have not been reported [3]. That a significant $\mathrm{Mg}$ deficiency has not been recognized may be attributed to only $1 \%$ of $\mathrm{Mg}$ is in the serum, therefore, a lack of sensitivity of serum Mg. Low dietary intakes, coupled with exercise-induced urinary losses, may eventually lead to an Mg deficiency. A deficiency of the mineral therefore has many physiological and exercise performance implications.

Further, clinical studies have described $\mathrm{Mg}$ influence on immune function and inflammation; with low magnesium stimulating immunopathological changes that are related to the initiation of a sequential inflammatory response. Low serum and dietary magnesium levels are strongly correlated with low grade systemic inflammation [5-8]. Experimental Mg deficiency produces a clinical inflammatory syndrome with leukocyte and macrophage activation, inflammatory cytokines released, and excessive production of free radicals. Results from animal studies have been corroborated in human responses, with $\mathrm{Mg}$ deficiency upregulating markers of inflammation and oxidative stress [5,9]. Mg deficiency elicits a systemic pro-inflammatory/prooxidant state, involving multiple tissues/organs.

Hypomagnesemia promotes low-grade inflammation as demonstrated by elevated concentrations of $\mathrm{C}$-Reactive Protein (CRP) and TNF- $\alpha[10,11]$. Low $\mathrm{Mg}$ is independently associated with elevated hsCRP levels $[11,12]$. Subjects who consume less than $75 \%$ of RDA were 1.94 times more likely to have elevated serum CRP levels than consuming above the RDA [13] and, in another study, the number of subjects with CRP $>3 \mathrm{mg} \cdot \mathrm{L}^{-1}$ significantly decreased from the lowest to the highest tertile of dietary $\mathrm{Mg}$ [14]. Adults who consumed less than the Mg RDA were 1.48-1.75 times more likely to have elevated CRP than adults who consumed more than the RDA [7]. Additionally, low $\mathrm{Mg}$ induces increases in circulating substance $\mathrm{P}$ that stimulates systemic inflammatory stress $[15,16]$.

There are various mechanisms that may explain the role of $\mathrm{Mg}$ in modulating immune function. $\mathrm{Mg}$ potentiates iron-transferrin binding, an important contribution to offsetting oxidative stress [17]. Mg reduces oxidative stress through stabilization of DNA. [18]. However, $\mathrm{Mg}$ acts as a natural calcium antagonist and the molecular basis for the inflammatory response is most likely strongly linked to the modulation of the intracellular calcium concentration [19]. Potential mechanisms include priming of phagocytic cells, opening of calcium channels, activation of N-Methyl-D-Aspartate (NMDA) receptors, and activation of the renin-angiotensin system [20]. Mg deficiency induces a systemic stress response through activation of the neuroendocrine axis. $\mathrm{Mg}$ has a strong influence on both nonspecific and specific immune responses, and research shows it is related to inadequate cellular and humoral immune responses. The mechanism is postulated to be the role of $\mathrm{Mg}$ deficiency that leads to the initiation of a sequential inflammatory response. Further studies are still needed to better elicit the role of $\mathrm{Mg}$ in human immune responses.

The specific mechanisms of the inflammatory response in $\mathrm{Mg}$ deficiency have not been elucidated. However, $\mathrm{Mg}$ deficiency results in a stress effect and increased susceptibility to physiological damage produced by stress. Stress activates the sympathetic nervous system and renin-angiotensin-aldosterone axis resulting in increased oxidative stress. Aldosteronism is immunostimulatory, as is commonly seen in congestive heart failure. The inflammatory syndrome induces mechanisms dependent on cytosolic calcium activation. These interrelationships support that the $\mathrm{Mg}$ effect on intracellular calcium homeostasis may be a common link between stress and inflammation [21].

Stressors include exercise; especially extreme physical activity of any type which may have implications for the immune system. Physical exercise may deplete $\mathrm{Mg}$, which together with a marginal dietary $\mathrm{Mg}$ intake may impair immune function [4]. Strenuous exercise induces immunodepression that is multifactorial in origin. Aspects of immune function can be depressed temporarily by either a single bout of very severe exercise or a longer period of excessive training. Depressed immunity may allow an episode of infection, particularly upper respiratory tract infections. Thus, the ability to perform physical work may be compromised.

Strenuous exercise induces pyrogenesis and suppresses cellular immunity leading to increased susceptibility to infections [22]. A common view is that Upper Respiratory Tract Infections (URTI) are increased in elite endurance athletes after single bouts of endurance exercise and during intensive training. The evidence is inconclusive, although exercise does alter the number and function of circulating innate immune cells [23]. Lymphocytosis is observed during and immediately after exercise, proportional to exercise intensity and duration, before returning to resting values normally within 24 h. Mobilization of $\mathrm{T}$ and $\mathrm{B}$ cell subsets is largely influenced by catecholamines. This apparent depression in acquired immunity appears to be related to exercise-induced elevated stress hormones. Salivary IgA underlying the alterations in mucosal immunity with acute exercise are probably under control of the sympathetic nervous system. There are numerous examples where exercise alters measures of immunity by $15-25 \%$ [23].

As with Mg studies, inflammatory markers escalate with strenuous exercise. CRP and TNFa increased significantly during the two weeks of exercise [24]. Four days of increased training load reduced running performance and altered the inflammatory response to highintensity intermittent exercise [25]. CRP is higher is contact sport than noncontact [26] and in exercising females compared to males [27]. Differences in the immune responses to exercise between healthy and illness-prone athletes may explain the greater incidence of URTI. The relationship between resting CRP concentrations and the peak pro and

*Corresponding author: L.R. Brilla, Ph.D., PEHR Department, Western Washington University, Bellingham, WA98225-9067, USA, Tel: 360-650-3056; Fax: 360-650-7447; E-mail: Lorrie.Brilla@wwu.edu

Received April 24, 2012; Accepted May 25, 2012; Published May 28, 2012

Citation: Brilla LR (2012) Magnesium Influence on Stress and Immune Function in Exercise. J Sports Med Doping Stud 2:111. doi:10.4172/2161-0673.1000111

Copyright: () 2012 Brilla LR. This is an open-access article distributed under the terms of the Creative Commons Attribution License, which permits unrestricted use, distribution, and reproduction in any medium, provided the original author and source are credited. 
anti-inflammatory responses to exercise supports involvement of CRP in the complex network regulating exercise-induced inflammatory disturbances [28]. Excessive cytokine release related to overtraining [29] may upset the balance between modulation of repair and development of inflammation and possible infections.

Other inflammatory markers are influenced by exercise, as well. Sprint intervals significantly increase inflammatory mediators, specifically IL-1 and IL-6 [30]. Endurance exercise lasting more than 12 hours showed that intensity, and not duration, is the main determinant of the IL-6 response [31]. Intense exercise game activity showed increases in serum cortisol and IL-6 and decreases in circulating T lymphocytes and natural killer cells, immediately post and $14 \mathrm{~h}$ after exercise until levels were restored [32].

Managing training to preserve immune health requires low to moderate volume and intensity [23] with gradual periodized increases in training volumes and intensity. Variety may limit stress; avoid excessively heavy training loads that could lead to exhaustion, illness or injury. Sufficient rest and recovery are essential and identification of performance deterioration and physical stress may ameliorate extreme immune changes. An appropriate exercise program may avoid high catecholamine levels $[18,33]$ and lessen $\mathrm{Mg}$ perturbations. It is also recommended to give attention to nutritional countermeasures to exercise-induced immune perturbations [34]. In general, undernourishment is associated with impaired immunity and should be addressed.

Mg improves markers of inflammation and oxidative stress, but supplementation studies have yielded inconsistent results [14]. It appears that an optimal magnesium intake may also be essential for antioxidant protection and for regulation of related responses, although more research is needed to describe the underlying mechanisms and to identify sufficient magnesium for performance [35,36]. Recently, it was shown that dietary magnesium is correlated with strength and power outcome measures [37]. In a study that excluded subjects who used supplements but controlled for chronic infection or inflammatory disease, a decline of serum magnesium with concomitant increases in the inflammatory marker, IL-6, were noted after running a marathon compared to baseline [38]. The baseline $\mathrm{Mg}$ status is implicated in whether the athlete will respond to supplementation; but, $\mathrm{Mg}$ status is difficult to obtain easily as the plasma levels are intransigent except for profound deficiency [1]. If $\mathrm{Mg}$ levels were so low to elicit defined plasma Mg deficiency, there would be severe compromise of physical performance. Very few studies have been conducted on this topic of $\mathrm{Mg}$, exercise, and immune function combination, to date. However, nascent evidence has been published recently that low dietary $\mathrm{Mg}$ is linked with increased immuno-inflammatory markers and associated with oxidative stress, as is intense exercise. Together with the similarities in outcomes of low $\mathrm{Mg}$ status and strenuous exercise, it is an area that warrants further inspection. $\mathrm{Mg}$ deficiency in athletes has not been robustly investigated regarding alterations in the immune system. The possibility exists that magnesium deficiency could contribute to the immunological changes observed after strenuous exercise [4].

\section{References}

1. Brilla LR, Lombardi VP (1999) Magnesium in Exercise and Sport: in Macromolecules, Electrolytes and Macroelements in Sports Nutrition, Boca Raton, FL: CRC Press 47-90.

2. Chen YJ, Chen HY, Wang MF, Hsu MH, Liang WM, et al. (2009) Effects of magnesium on exercise performance and plasma glucose and lactate concentrations in rats using a novel blood-sampling technique. Appl Physiol Nutr Metab 34: 1040-1047.
3. Nielsen FH (2010) Magnesium, inflammation, and obesity in chronic disease. Nutr Rev. 68: 333-340.

4. Laires MJ, Monteiro C (2008) Exercise, magnesium and immune function Magnes Res 21: 92-96

5. Rayssiguier Y, Gueux E, Nowacki W, Rock E, Mazur A (2006) High fructose consumption combined with low dietary magnesium intake may increase the incidence of the metabolic syndrome by inducing inflammation. Magnes Res 19: $237-243$

6. Song Y, Ridker PM, Manson JE, Cook NR, Buring JE, et al. (2005) Magnesium intake, C-reactive protein, and the prevalence of metabolic syndrome in middleaged and older U.S. women. Diabetes Care 28: 1438-1444

7. King DE, Mainous AG 3rd, Geesey ME, Woolson RF (2005) Dietary magnesium and C-reactive protein levels. J Am Coll Nutr 24: 166-171.

8. Rodriguez-Morand M, Guerrero-Romero F (2004) Elevated concentrations of TNF-alpha are related to low serum magnesium levels in obese subjects. Magnes Res 17: 189-196.

9. Tejero-Taldo MI, Kramer JH, Mak luT, Komarov AM, Weglicki WB (2006) The nerve-heart connection in the pro-oxidant response to Mg-deficiency. Heart Fail Rev 11: 35-44.

10. Guerrero-Romero F, Bermudez-Peña C, Rodríguez-Morán M (2011) Severe hypomagnesemia and low-grade inflammation in metabolic syndrome. Magnes Res 24: 45-53.

11. Rodríguez-Morán M, Guerrero-Romero F (2008) Serum magnesium and C-reactive protein levels. Arch Dis Child 93: 676-680.

12. Guerrero-Romero F, Rodríguez-Morán M (2006) Hypomagnesemia, oxidative stress, inflammation, and metabolic syndrome. Diabetes Metab Res Rev 22: 471-476.

13. King DE, Mainous AG 3rd, Geesey ME, Ellis T (2007) Magnesium intake and serum C-reactive protein levels in children. Magnes Res 20: 32-36.

14. Bo S, Durazzo M, Guidi S, Carello M, Sacerdote C, Silli B, et al. (2006) Dietary magnesium and fiber intakes and inflammatory and metabolic indicators in middle-aged subjects from a population-based cohort. Am J Clin Nutr 84: 1062 1069.

15. Weglicki WB, Chmielinska JJ, Kramer JH, Mak IT (2011) Cardiovascular and intestinal responses to oxidative and nitrosative stress during prolonged magnesium deficiency. Am J Med Sci 342: 125-128.

16. Kramer JH, Spurney C, lantorno M, Tziros C, Mak IT, et al. (2009) Neurogenic inflammation and cardiac dysfunction due to hypomagnesemia. Am J Med Sci 338: 22-27.

17. Parent ME, Zemel MB (1989) Magnesium potentiation of iron-transferrin binding. Life Sci 44: 1007-1012.

18. Rowe WJ (2012) Correcting magnesium deficiencies may prolong life. Clin Interv Aging 7: 51-54

19. Bussière FI, Gueux E, Rock E, Mazur A, Rayssiguier Y (2002) Protective effect of calcium deficiency on the inflammatory response in magnesium-deficient rats. Eur J Nutr 41: 197-202.

20. Mazur A, Maier JA, Rock E, Gueux E, Nowacki W, et al.(2007) Magnesium and the inflammatory response: potential physiopathological implications. Arch Biochem Biophys 458: 48-56.

21. Rayssiguier $Y$, Libako $P$, Nowacki W, Rock E (2010) Magnesium deficiency and metabolic syndrome: stress and inflammation may reflect calcium activation. Magnes Res 23: 73-80.

22. Suzuki K, Nakaji S, Yamada M, Totsuka M, Sato K, et al. (2002) Systemic inflammatory response to exhaustive exercise. Cytokine kinetics. Exerc Immunol Rev 8: 6-48.

23. Walsh NP, Gleeson M, Shephard RJ, Gleeson M, Woods JA et al. (2011) Position statement. Part one: Immune function and exercise. Exerc Immuno Rev 17: 6-63.

24. Andersson J, Jansson JH, Hellsten G, Nilsson TK, Hallmans G, et al. (2010) Effects of heavy endurance physical exercise on inflammatory markers in nonathletes. Atherosclerosis 209: 601-605.

25. Slattery KM, Wallace LK, Bentley DJ, Coutts AJ (2012) Effect of training load on simulated team sport match performance. Appl Physiol Nutr Metab 37: 315 322 
Citation: Brilla LR (2012) Magnesium Influence on Stress and Immune Function in Exercise. J Sports Med Doping Stud 2:111. doi:10.4172/21610673.1000111

26. Singh TK, Guelfi KJ, Landers G, Dawson B, Bishop D (2011) A comparison of muscle damage, soreness and performance following a simulated contact and non-contact team sport activity circuit. J Sci Med Sport 14: 441-446.

27. Dopsaj V, Martinovic J, Dopsaj M, Stevuljevic JK, Bogavac-Stanojevic N (2011) Gender-specific oxidative stress parameters. Int J Sports Med 32: 14-19.

28. Cox AJ, Pyne DB, Gleeson M, Callister R (2009) Relationship between C-reactive protein concentration and cytokine responses to exercise in healthy and illness-prone runners. Eur J Appl Physiol 107: 611-614.

29. Main LC, Dawson B, Heel K, Grove JR, Landers GJ, et al. (2010) Relationship between inflammatory cytokines and self-report measures of training overload. Res Sports Med 18: 127-139.

30. Meckel Y, Nemet D, Bar-Sela S, Radom-Aizik S, Cooper DM, et al. (2011) Hormonal and inflammatory responses to different types of sprint interval training. J Strength Cond Res 25: 2161-2169.

31. Wallberg L, Mikael Mattsson C, Enqvist JK, Ekblom B (2011) Plasma IL-6 concentration during ultra-endurance exercise. Eur J Appl Physiol 111: 10811088.

32. Cunniffe B, Hore AJ, Whitcombe DM, Jones KP, Baker JS, et al. (2010) Time course of changes in immuneoendocrine markers following an international rugby game. Eur J Appl Physiol 108: 113-122.

33. Epel ES, Lin J, Wilhelm FH, Wolkowitz OM, Cawthon R, et al. (2006) Cell aging in relation to stress arousal and cardiovascular disease risk factors. Psychoneuroendocrinology 31: 277-287.

34. Walsh NP, Gleeson M, Pyne DB, Nieman DC, Dhabhar FS, et al. (2011) Position statement. Part two: Maintaining immune health. Exerc Immunol Rev 17: 64-103.

35. Nielsen FH, Lukaski HC (2006) Update on the relationship between magnesium and exercise. Magnes Res 19: 180-189.

36. Rosanoff A, Weaver CM, Rude RK (2012) Suboptimal magnesium status in the United States: are the health consequences underestimated? Nutr Rev 70 153-164.

37. Santos DA, Matias CN, Monteiro CP, Silva AM, Rocha PM, et al. (2011) Magnesium intake is associated with strength performance in elite basketball, handball and volleyball players. Magnes Res 24: 215-219.

38. Scherr J, Schuster T, Pressler A, Roeh A, Christle J, et al. (2012). Repolarization perturbation and hypomagnesaemia after extreme exercise. Med Sci Sports Exerc. 